\title{
Aaron Antonovsky's Development of Salutogenesis, 1979 to 1994
}

\author{
Hege Forbech Vinje, Eva Langeland, and Torill Bull
}

\section{Introduction}

\author{
"I hope it will become clear in due course that my concern is no \\ mere semantic quibble and that (here), as in all of science, how \\ one poses the question is crucial to the direction one takes in \\ looking for the answers" (Antonovsky, 1979, p. 12).
}

When a person thinks seriously about a topic over a period of about three decades, it is a sign of good thinking and personal development if, at the end of that period, he/she is no longer in total agreement with former ideas. Adventures along the road become the germ (to use Antonovsky's own expression) of new ideas and layers of understanding. So was also the case with the development of the Salutogenic Model of Health (SMH), a development described by Antonovsky himself in retrospect as a 'personal odyssey' over decades (Antonovsky, 1990). While chapter three portrays Antonovsky, the man and the researcher, this chapter portrays the SMH and its development along with life events of its creator until the untimely death of Antonovsky in 1994. The chapter is based on the authorship of Antonovsky himself. Papers written in his last years, in which he looks back and comments on how his thinking developed, have been of particular value. These papers come in addition to the publications in which he originally introduced his ideas. In the $\mathrm{SMH}$, there are important concepts the development of which we trace in this chapter:

H.F. Vinje $(\square)$

Department of Health Promotion, Faculty of Health Sciences, University College of Southeast Norway, Campus Vestfold, Norway e-mail: hege.f.vinje@hbv.no; hege.f.vinje@usn.no

E. Langeland

Department of Nursing, Faculty of Health and Social Sciences, Bergen University College, Bergen, Norway

e-mail: eva.langeland@hib.no

T. Bull

Department of Health Promotion and Development, Faculty of Psychology, University of Bergen, Bergen, Norway e-mail: torill.bull@iuh.uib.no stress, breakdown, resources, Sense of Coherence (SOC), and health.

Antonovsky departs, in his two major books (Antonovsky, 1979, 1987) from the traditional medical view of homeostasis being the basic human condition, and introduces the fundamental philosophical view of "the human organism as prototypically being in the state of heterostatic disequilibrium as the heart of the salutogenic orientation" (Antonovsky, 1987, p. 130). The release of Health, Stress and Coping in 1979 was a culmination of 15 years of work, during which he came to understand that disease, illness, and entropy (decline into disorder) are the norm rather than the exception to a rule of otherwise selfregulated homeostatic processes occasionally being disturbed with resulting pathology. He found it to be a futile task to try to understand and control every single factor that might lead to this or that particular disease. A more fruitful approach would be to focus on what he found to be the overall problem of active adaptation to an environment in which stressors are omnipresent and inevitable. He presented the term negative entropy (Antonovsky, 1987, p. 9) in which the goal was to search for useful inputs to the sociocultural context, the physical environment, and into the organism down to the cellular level to counter the normal tendency of entropy. So, negative entropy or negentropy as he also termed it, is actually something positive.

In his efforts to study health instead of disease, Antonovsky coined his famous new word: "salutogenesisof the origins (genesis) of health (saluto)" (Antonovsky, 1979, preface vii), the intriguing question being: what are the origins of health? In the course of his research, Antonovsky correspondingly offered an answer to the question: "The origins of health are to be found in a sense of coherence" (Antonovsky, 1979, preface vii). This question and the answer constitute the SMH, the development of which is the focus of this chapter. In his descriptions of the model, most importantly of the process developing it, he points to the struggles it entailed for him, and for other 
researchers and practitioners, to move from one paradigm to another: "I have no illusions. A salutogenic orientation is not likely to take over. Pathogenesis is too deeply entrenched in our thinking..." (Antonovsky, 1996b, p. 171). Antonovsky urged, nevertheless, researchers of different professions, and with use of different methodologies, to work together to bring the knowledge of the origins of health increasingly further.

Antonovsky worked on the SMH for more or less 30 years. The first 15 years resulted in his book Health, Stress and Coping in 1979, and the presentation of SMH in its entirety. The next 15 years he was improving, refining, and cultivating the understanding of the model and the elements in it. The release of his 1987 book Unravelling the Mystery of Health represented a peak in his career. This release was originally intended to be a revised version of Health, Stress and Coping, but ended up being a whole new book, primarily presenting and explaining the concept of Sense of Coherence, his answer to the salutogenic question. His second book became a huge success and is translated into several languages.

In the preface of his first book, Antonovsky (1979) points out that he offers no easy solutions to the salutogenic question, and that he does not shy away from technical discussions when needed. His writings are directed not only to his colleagues in medical sociology, but also to sociologists, psychologists, psychiatric nurses, physicians, healthcare organizers, epidemiologists, architects, community organizers, and even more, who professionally or personally want to understand and enhance the adaptive capacities of human beings (Antonovsky, 1979, preface viii). His rather wide scope of intended audience is also reflected in the cross section of where he finds theoretical and intellectual inspiration. He expresses indebtedness to students, research assistants, and colleagues, without whom he would not have reached as far as he did. Repeatedly he points out the necessity and value of students' and peers' criticism not only for the ideas he took from them, but also for the intellectual challenge in the need to explain why. Throughout Health, Stress and Coping especially, but also in Unravelling the Mystery of Health Antonovsky specifies to whom he owes his intellectual debts. He names and credits scholars such as Hans Selye, René Dubos, George Engel, Thomas Holmes, Richard Rahe, John Cassel, and Melvin Kohn. As he believes to have broken new ground, he also claims to see echoes of his ideas everywhere (Antonovsky, 1987, p. 34). Although he says he finds evidence of the influence of great thinkers in his work, he describes a feeling of relative isolation when introducing the concept of salutogenesis and developing the SMH. As he narrates every other researcher of the time focused on the need to explain pathology, his feeling of isolation intensified with the introduction of the sense of coherence, the answer to the salutogenic question (Antonovsky, 1987, p. 33). In developing the SMH, not only did he detach himself from his earlier work, but also from the work of just about everyone else at the time. Around the time of the release of Health, Stress and Coping he finds, however, that the salutogenic question is increasingly asked, and he is intrigued to notice that serious research studies at least partly congruent with the SOC concept are being performed. He no longer feels alone as elements, variants, and alternative understandings of health and illness in the social sciences are surfacing (Antonovsky, 1987, p. 34). Antonovsky humbly credits this development primarily to the serious research of colleagues, and not so much to his own work. He dedicates a chapter in his 1987 book to convergences, discrepancies, and disagreements of the research of Suzanne Kobasa, Thomas Boyce, Rudolf Moos, Emmy Werner, and David Reiss and demonstrates once more how his ideas and theories develop in interaction with the theories of other scholars.

In all his writings about the SMH, Antonovsky gives a somewhat personalized account of how he came to work on the subject at hand, he presents challenges he encounters on his way and he clarifies and explains how he moves ahead and reaches the point at which he stands when writing this particular book or paper. Apparently he learnt this approach from Oriental scholars (Antonovsky, 1979, prologue 1). Being so detailed about his research process makes a very interesting read, and gives the impression of a humble scholar, on his way, inviting other researchers in on his reflections. Antonovsky declares that the $\mathrm{SMH}$ is merely one part of the conceptualization of what he finds to be one of the greatest mysteries of the study of human beings: "How do we manage to stay healthy?"(Antonovsky, 1979, preface vii). On a hopeful note, in Health, Stress and Coping he expresses a wish that the salutogenic question is convincing enough for researchers to take up the gauntlet and develop the model further; of which this book is a clear demonstration.

\section{Stress Research: The Principal Note}

At the outset Antonovsky was not particularly interested in stress (Antonovsky, 1990). In retrospect, however, he singles out research (Hollingshead \& Redlich, 1958; Kardiner \& Ovesey, 1951; Selye, 1956) causing him to stop a little and reflect upon questions relevant to stress during his training years in the Yale Sumner-Keller anthropological tradition in the fifties. Nonetheless, at the time he found them peripheral to his main interests, and he did not believe he would spend most of his career studying the stress process. His major interests during these formative years were in "culture and personality, stratification and ethnic relations" (Antonovsky, 1990, p. 71). Growing up as he did in 
New York, being the son of Jewish parents, one can assume this interest was awakened by his exposure to both Jewish and North-American culture, cultures which he contrasted in several publications (see for example Antonovsky, 1971). In 1955/1956, Antonovsky finished his doctoral dissertation in which he investigated cognitive coping responses to socially structured psychosocial stressors (Antonovsky, 1979). Minority groups and marginal social situations were the focus of his doctoral research. He continued down this path for six more years, though his focus shifted to the organizational response on a group level to immigration and the stressors of low income and discrimination (Antonovsky, 1979). This shift was brought on by his work on the history of the Jewish labor movement in the United States (Antonovsky, 1961), and as a director of the New York State Commission Against Discrimination. The organizational response on a group level to the stressors of poverty and immigration became a major concern and he initiated several studies on the consequences of these stressors (Antonovsky \& Lorwin, 1959). So although he also worked in a series of projects in the 1950s not connected to his main interests (an experience well known to many a young researcher), stressors and coping responses on both individual and group levels were of particular interest to him. He describes himself as an anthropologically oriented sociologist being interested in understanding the specifics of a society's competence-socioculturally_at coping with stressors it faces (Antonovsky, 1979). In retrospect, in his Odyssey article (Antonovsky, 1990), he presents himself as a sociologist of health involved in studying the stress process, and he returns some 25 years describing the starting point as being his work on life stressors.

After migrating to Israel in 1960, Antonovsky's research engagements brought more stimulation for the work he was to pursue for the rest of his life, and put him on the path of becoming a medical sociologist (Antonovsky, 1990, p. 72). He accepted a post at the Israel Institute for Applied Social Research in Jerusalem and begun teaching in the Department of Social Medicine. Together with Judith Shuval he started a research project on the latent functions of healthcare institutions (Schuval, Antonovsky, \& Davies, 1970), and projects on coronary artery disease, multiple sclerosis, menopause, and series of studies on social class and aspects of health and disease followed (Antonovsky, 1979, the author, xiv). In 1963, he was invited by colleagues in neurology to take part in the design of an epidemiological study on multiple sclerosis, mainly because he had experience in survey research. Antonovsky joined because the study questionnaire included items on this particular area of interest for him-sociocultural factors (Antonovsky et al., 1965; Antonovsky \& Kats, 1967). Included among the items was a list of stressors in objective form, such as social class and poor living conditions. This was part of Antonovsky's turn toward a focus on social class, morbidity, and mortality. Studies from this period show his commitment to hypothesizing a direct link between stressors and disease, and especially social class and disease. He defined stressors objectively as those experiences that anyone anywhere would agree were stressors, pointing to going hungry for a long period of time as his illuminating example. His primary concern at this stage was to bring the data of stressors and disease together rather than going deeper and behind the data and ask Why? (Antonovsky, 1967a, 1967b, 1968).

In this period, he also coedited the book Poverty and Health with his colleagues in the field of sociology (Kosa, Antonovsky, \& Zola, 1969). Together they pose the question: "What are the stressors in the lives of poor people that underlie the brute fact that, with regard to everything related to health, illness and patienthood, the poor are screwed?" (Antonovsky, 1979, p. 3). The Why question started forcing itself to the front of his interest. Reflecting about this period of his work Antonovsky recounts this is the time he starts to depart from what he calls the pathogenic orientation (Antonovsky, 1990). Fueling his pondering was Marc Fried's writings on social differences in mental health in the Poverty and Health book. Not only were the stressors important, Fried argued, the poor had fewer resources to battle these stressors (Antonovsky, 1979, p. 3). The book clearly stated the link between poverty and poorer health, bringing the sociological insight that poorer health was not only due to lower quality of health services to the poor, but also to the conditions to which the poor were exposed. As Antonovsky later wrote, the poorest life class "had it rough down the line, whatever the dependent variable might be. This was the class which clearly had the highest stress load" (Antonovsky, 1990, p. 73). In addition, there was another characteristic of the stress of the poor, and the minority groups, that gave insight to the Why question: namely the constancy of the stressors.

\footnotetext{
"The constancy of imposed stressors in such life situations, the continuous emergencies life presents, make it immensely difficult to resolve tension. Life for even the fortunate among us is full of conflict and stressors, but there are many breathing spells" (Antonovsky, 1990, p. 74).
}

To understand the link between stressors and disease, Antonovsky recounts struggling with the methodological problem of getting the right list of life events or stressors to ask about in a survey. Eventually he came to terms with this not being a methodological but rather a philosophical issue; a result of what he called the pathogenic orientation, or the Parsonian view of social existence, referring to Parsons' sociological theory of the time (Parsons, 1951). At the time, research focusing on stressors tended to assume life as inherently stable and smooth with major stressors only occasionally occurring. Antonovsky (1990) claimed, however, this view not helpful and rather inadequate in 
understanding the stress process. A more fruitful vision is to see life as turbulent and inherently full of conflicts and stressful. Once again, he drew inspiration from Fried and what he called chronic life strain, referring to long-lasting structural and cultural situations such as poverty, unemployment, marginality, etc, a sad fact of the lives of many persons (Antonovsky, 1990, p. 73). It is important, Antonovsky argued, to understand the ongoing strain of such situations as these are also the sources of many of the major life events, as well as of the daily hassles, which people face.

Continuing undisturbed along this line of reasoning in recapturing Antonovsky's research would however make us overlook another important development that came as a result of a parallel development: a study of psychosocial risk factors in coronary artery disease in the form of stressors in immigrants to Israel from North America (Antonovsky, 1967b). Being in fact a respondent in his own study, Antonovsky made the observation that yes, he was exposed to stressors-but they did not result in illness, he was coping successfully. This led him to focus on how specific serious stressors were dealt with (Antonovsky, 1990, p. 74).

\footnotetext{
"This step marked the germ of the distinction I now make between tension and stress. I had not, and do not now, deny the potential illness consequences of many stressors. Well into the 1970s, I still tended to regard all stressors as unfortunate and pathogenic. But I had begun to ask: What really happens when one encounters a stressor?"
}

The observation was made that exposure to stressors did not invariably lead to stress and illness. Stressors of various kinds created immediate tension in an organism, but if it was resolved it did not result in stress, which was the health-damaging condition one needed to avoid. Coping and tension management emerged as important concepts and intervening variables between tension and stress/illness. At this point in his research there was a decisive change in his thinking, and in his scholarly pondering he turned to both Lazarus (Lazarus \& Cohen, 1977) and Selye (1956) for inspiration. In brooding the why-question he realized that it is not just the stressors that are vital in this picture, also the poor have fewer resources in order to cope. There will be a difference if two people are exposed to the same stressor and one of them has lots of resources, while the other has practically none. Both the experience and its consequences will be different for the two. Antonovsky's study on cardiovascular disease and stress showed a link between the two. He presented these findings to an audience and was asked a thought-provoking question by Professor J. N. Morris: "Why just cardiovascular disease, why not cancer or any other disease for that matter?" (Antonovsky, 1972, p. 537). This set Antonovsky thinking, and the result was his realization that he was not really interested in any specific diseases, be it cancer or heart disease. He was interested in the illness consequences of psychosocial stressors, the breaking down process taking place no matter how the consequence was expressed (Antonovsky, 1979, prologue 4.):

\begin{abstract}
"And then it struck me. By God, Morris is right. I am not interested in heart disease or multiple sclerosis or cancer; I am interested in breakdown. This, then, is the origin of my first major departure from the mainstream."
\end{abstract}

Antonovsky realized he was interested in a general state, which he wished to call dis-ease. However, he found this term impractical because it would be hard, he believed, to achieve a clear enough distinction from disease. There are unfortunate examples in publications since Antonovsky, in which "dis-ease" turned into "disease", the hyphen being ignored. Antonovsky's point has then not been communicated. In an effort to help this important distinction come across, we will in this chapter use a slash (dis/ease) instead of a hyphen. Hence, he landed on the term breakdown which Professor Morris had used, and whom he credited in a later paper known as his breakdown paper (Antonovsky, 1972). It was, for technical reasons, not published until 1972, but the main message in this paper was that stressors, unsuccessfully confronted, lead on to breakdown. "It contained the first answer to the problem posed by the distinction between tension and stress, an answer expressed in the concept generalized resistance resources" (Antonovsky, 1990, p. 76).

As this outline shows, the late 1960s seem important years to the development of his model. Antonovsky claims 1967 and 1968 as especially vital years in this respect (Antonovsky, 1979, 1990). In the years to come, he was committed to conceptualizing his insights, starting with an explicit focus on resources.

\section{General Resistance Resources: A Shift to Another Key}

Because people meet such a variety of demands, Antonovsky found it useful to focus on understanding the generalized resistance resources (GRRs) because they could be applied to a wide range of demands or stressors. He proposed to distinguish between two kinds of problems (1) the classical medical problem of why an individual or a group have the disposition for a particular disease and (2) the problem of experiencing dis/ease or breakdown, unrelated to diagnosis and disease. The latter of these two became his focus. Further he theorized that all diseases have something in common, and that there are GRRs to counteract all of these (Antonovsky, 1979). Once again he turned to the work of Selye and found particular inspiration in Selye's term general adaptation syndrome (Selye, 1956, 1975). Antonovsky (1979, prologue 5) argues: “it seems imperative 
to focus on developing a fuller understanding of those generalized resistance resources which can be applied to meet all demands."

In 1967, Antonovsky made the comment that "the impact of a given external situation upon a person is mediated by the psychological, social and cultural resources at his disposal" (Antonovsky \& Kats, 1967, p. 16). However, Antonovsky later calls this mentioning of resources essentially a remark made in passing (Antonovsky, 1974, p. 246). In the breakdown paper, he returns to the issue of resources with a clear intent and introduces his most general definition of a GRRs: "any characteristic of the person, the group, or the environment that can facilitate effective tension management" (Antonovsky, 1972, p. 99). In the same paper, he classifies three large groups of resources (1) adaptability on the physiological, biochemical, psychological, cultural, and social levels; (2) profound ties to concrete, immediate others; and (3) commitment of and institutionalized ties between the individual and the total community (Antonovsky, 1972, p. 100). Nevertheless, his formal definition of GRRs was not published until 1979 (see Fig. 4.2). In Health, Stress and Coping, he also emphasized the importance of specific resistance resources (SRRs), as he found them both numerous and frequently beneficial in specific circumstances of tension (Antonovsky, 1979, p. 99):

\footnotetext{
"They (SRRs) are many and are often useful in particular situations of tension. A certain drug, telephone lifelines of suicide-prevention agencies or an understanding look in the eyes of an audience to whom one is lecturing can be of great help in coping with particular stressors. But these are all too often matters of chance or luck, as well as being helpful only in particular situations."
}

Summing up, one important observation from this period was that stressors do not have to lead to disease, because tension management and coping might function as intervening variables (effect modifiers). The degree to which people were exposed to stress, and the degree to which one had resources to cope, varied. Sure, stressors created tension, but this tension could be successfully resolved. Influenced by René Dubos and his warnings against the mirage of health and the escalating wars against every possible disease (Dubos, 1960), Antonovsky moved on to explore the term adaptability in psychological, social, and cultural contexts. Antonovsky called it active adaptation, and presented is as a complementary term to the magic bullet in the pathogenic paradigm; "Salutogenesis, (...) leads us to focus on the overall problem of active adaptation to an inevitably stressor-rich environment" (Antonovsky, 1987, p. 9).

In his accounts from 1990, Antonovsky finds himself at this time in his work nonetheless still firmly grounded in pathogenic thinking. He saw stressors as a threat and coping as a mean to prevent illness and disease. However, in
1967-1968 there was yet another important development. Antonovsky was, parallel to the heart disease paper, working on a study of menopausal women (Antonovsky, Maoz, Dowty, \& Wijsenbeek, 1971). One finding was that women who had been exposed to severe stressors did poorer in later stages of life. One of the severe stressors given attention in this study was having experienced Holocaust (Antonovsky preferred to call this a horror, finding stressor to be a too mundane expression). Most of the women having experienced Holocaust did significantly poorer than other women did. However, a third of them did no poorer at all! This caused Antonovsky to ask, "What was the miracle?" (Antonovsky, 1990, p. 76). Here, we see an example of Antonovsky focusing on the deviant case (see section 'Harmonizing: SMH's relevance for health promotion' for further comments on this principle). Included in the questionnaire for the menopause study were items on social integration. Antonovsky commented that this study, being prior to the main development of the later so popular concept social support, rather asked how much do you feel you are needed by your spouse, children, etc. The focus was being turned on its head toward being on the giving end rather than the receiving end of support, and this he commented in recollection, was the germ of the meaningfulness element of sense of coherence (Antonovsky, 1990, p. 75).

The early 1970s therefore sees Antonovsky as having concluded that he was not interested in specific diseases but in a general state of breakdown which comes because of unsuccessful confronting of stressors.

\footnotetext{
“...breakdown is a result of unresolved disturbance of homeostasis....It is not, then, the imbalance which is pathogenic. It is, rather, the prolonged failure to restore equilibrium which leads to breakdown. When resistance resources are inadequate to meet the demand, to resolve the problem which has been posed, the organism breaks down" (Antonovsky, 1972, p. 541).
}

The dependant variable that interested him was breakdown, and the independent variables of his concern were the GRRs. The level of stressors, whether objectively or subjectively defined, was not at this point of any interest to him (Antonovsky, 1979, prologue 5). A person could cope successfully with stressors through application of resources, called GRRs, thereby preventing the tension caused by stressors being transformed into stress.

To Antonovsky it was obvious that having resources, being conscious about them and having ability to use them to counter stressors was an important factor in avoiding dis/ease, or breakdown. He had already coined the concept generalized resistance resources (Antonovsky, 1972, p. 99). He also had observed the miracle of people doing well despite horrible experiences. How was that possible (Antonovsky et al., 1971)? Furthermore, he had conducted a community health study in Beersheba, finding a link 
between GRRs and health, later to be published as a chapter in a book edited by the acknowledged stress-researchers Barbara and Bruce Dohrenwend (Antonovsky, 1974). In 1973, the Beersheba community health study was presented at a large stress research meeting in New York, arranged by the very same Dohrenwends. At this point, GRRs had not yet been carefully defined theoretically. Antonovsky states:

"... there was some general sense that it referred to some resource which, intuitively, we thought was good to have, an intuition sometimes supported by empirical data. (...) we were all dealing with the lack of GRRs, and hypothesizing that people with high stressor loads who lacked GRRs would become ill" (Antonovsky, 1990, p. 76).

Though elements of the SMH were taking shape, Antonovsky was still not ready to formulate the full model. He describes a development over 10 years from 1968 (Antonovsky, 1990, p. 76):

\begin{abstract}
"By 1968, as I have indicated, I had realised that I was interested in dis/ease, not in diseases. But it took almost another decade, involved in the growing awareness of the ubiquitousness of stressors and a greater focus on resistance resources, before I was able to take the next step."
\end{abstract}

One of the important happenings during this decade was that he moved from Jerusalem to Beersheba in 1973. Helping setting up a community and primary care oriented medical school there had the consequence that he thoroughly thought about the kind of doctors he and they wanted to educate (Antonovsky, 1990, p. 76). Starting by turning to the GRRs concept, still not properly defined, he was inspired to formulate his research findings and theoretical ideas into a fuller picture as he developed the curriculum. He chose to call the new department within the school The Sociology of Health (not medical sociology, which was commonly used in the field elsewhere). As an indication of the zeitgeist, he recounts that the Research Committee of the International Sociological Association needed 13 years to change its name from Medical Sociology to the Sociology of Health (ibid, p. 76). Bringing forth the illustration of the river of life and the bias of the downstream focus that was debated at the time, Antonovsky wanted to educate doctors who devoted their energies to prevent people from being pushed into the river, rather than pulling them out at the downstream end. Over time, however, Antonovsky's perspective on stress and health developed, and he came to acknowledge that there are no people on the river banks - all are in the river, as all are exposed to stressors and illness. "Of course we differ on how close we are to drowning. But as my friend and colleague Rose Coser has taught me, 'we are all terminal cases"' (Antonovsky, 1990, p. 76).

This differentiated his view on health and illness from that of colleagues - we are not all well and occasionally fall ill, we are all on a continuum with different degrees of health (Antonovsky, 1990, p. 76):

\begin{abstract}
"It was at this point that I began to see the work of my colleagues in stress research as being characterized by a pathogenic orientation. They were asking: 'What makes people have a heart attack? Develop cancer? And so on?' I had earlier moved to the question 'What makes people sick?' But now I took a decisive further step. It was not only a matter of standing the question on its head and asking 'What makes people healthy?' I proposed asking, rather, 'What moves people toward the health end of the health ease-dis/ease continuum?"
\end{abstract}

Because he was not a clinician himself, he argued, he was not in the habit of categorizing people as healthy or sick. Moreover, he understood that his formation of stressors and GRRs moved him much further than the preventive medicine perspective (Antonovsky, 1990). He discussed the need to exceed the traditional medical dichotomy of sick/healthy in the pathogenic paradigm. From the perspective of heterostasis and entropy, it was obvious to him that every one of us, as long as we live, is in part healthy and in part sick (Antonovsky, 1979, prologue 5). He called this the health ease-dis/ease continuum, or breakdown continuum, and he defined the construct operationally in a mapping sentence (Fig. 4.1).

He became, however, increasingly more reluctant to using the word breakdown:

\begin{abstract}
"I used the term breakdown (in 1972). I then indicated that I would have preferred to use dis/ease.....The term breakdown seems to have caught on, and I shall continue to use it, asking the reader to bear with me and to keep in mind that the fully appropriate term is the ease-dis/ease continuum." (Antonovsky, 1979, p. 57)
\end{abstract}

In 1979, Antonovsky recollects, however, that the very use of the term breakdown points to the fact that he in the early 1970s had a pathogenic orientation, "Like everyone else," he adds (Antonovsky, 1979, prologue 5). The realization of the 'health ease-dis/ease continuum' extended his interest from Holocaust survivors to all humans. As some were doing better than others were, he finally in the mid-1970s formulated the question: "What moves people towards the health end of the health easedis/ease continuum?" He needed a term for this-for the movement toward the health end of the continuum-and landed on salutogenesis, which he had himself used in another context 10 years earlier. In recollection, he remarks (Antonovsky, 1996b, p. 171): "I did not really depart from the mainstream until I coined the term salutogenesis in 1978." Later in this chapter, we focus more on Antonovsky's development of the health concept, but for now we follow Antonovsky to Berkeley, where important developments took place. In the Odyssey (Antonovsky, 1990), he narrates that he leaves for his sabbatical with a nagging sense of discontent. While 
Fig. 4.1 Mapping sentence definition of health ease-dis/ease continuum (Antonovsky, 1987, p. 65)
Breakdown is any state or condition of the human organism that is felt by the individual to be

that is felt by him/her to be

that would be defined by the professional health authorities as a

and that would be seen by such authorities as requiring

\section{A. Pain}

$\left\{\begin{array}{l}\text { 1. not at all } \\ 2 . \text { mildly } \\ \text { 3. moderately } \\ \text { 4. severely }\end{array}\right\} \quad$ painful;

B. Functional Limitation

$\left\{\begin{array}{l}\text { 1. not at all } \\ \text { 2. mildly } \\ \text { 3. moderately } \\ 4 \text {. severely }\end{array}\right\} \begin{aligned} & \text { limiting for the } \\ & \text { performance of life } \\ & \text { activities self-defined } \\ & \text { as appropriate; }\end{aligned}$

C. Prognostic Implication

$\left\{\begin{array}{l}\text { 1. not acute or chronic } \\ \text { 2. mild, acute, and self-limiting } \\ \text { 3. mild, chronic, and stable } \\ \text { 4. serious, chronic, and stable } \\ \text { 5. serious, chronic, and degenerative } \\ \text { 6. serious, acute, and life-threatening }\end{array}\right\}$

condition;

D. Action Implication

$\left\{\begin{array}{l}\text { 1. no particular health-related action } \\ \text { 2. efforts at reduction of known risk factors } \\ \text { 3. observation, supervision, or investigation } \\ \text { by the health care system } \\ \text { 4. active therapeutic intervention }\end{array}\right\}$. being satisfied with posing the radically new salutogenic question in the mid-70s, he was not completely happy with his tentative answer, GRRs.

\section{Sense of Coherence: Successive Notes of the Scale}

With many ideas in his luggage, he left for a sabbatical at Berkeley in 1977. During this year, he wrote Health, Stress and Coping published in 1979 and which: "contained the first full statement of what I call the salutogenic model and its core concept, the sense of coherence" (Antonovsky, 1990, p. 77). He approached the salutogenic question, and knew he already had part of the answer: GRRs. Working on his data using a technique called smallest space analysis, which renders a graphic map of variables; he constantly saw a factor $X$ turning up, being closer to health than any of the other GRRs were. Was it a common element of all GRRs? What did GRRs have in common that led to health? Antonovsky knew social support was a GRR, and that Cassel (1976) theorized that social support worked through providing various kinds of feedback. Antonovsky theorized that all GRRs provide feedback of some kind, “. . . sending messages like: Here is the right track; you can handle things; you are of worth" (Antonovsky, 1990, p. 78). He was now in the position where he could formally define GRRs (Fig. 4.2).
Furthermore, he could also now describe factor $\mathrm{X}$, that operated at a different level than the other GRRs, revealing a phenomenon about a specific orientation to life. Repeated and consistent messages of the kind described just above led one to become high on $\mathrm{X}$, while confusing and negative messages led one to become low on X. He called X Sense of Coherence (SOC), and defined it the following way (1979, p. 123):

"A global orientation that expresses the extent to which one has a pervasive, enduring though dynamic, feeling of confidence that one's internal and external environments are predictable and that there is a high probability that things will work out as well as can reasonably be expected."

In the preface of Unraveling the Mystery of Health, Antonovsky credits his wife Helen as the one who proposed the term the sense of coherence. Being a developmental psychologist with anthropological training, she was able to grasp exactly what he wished to say, and he considered her a most competent professional critic (Antonovsky, 1987, preface xviii). Antonovsky could now depict the model in full, and Fig. 4.3 shows how it was rendered in the 1979 book. In 1990, Antonovsky comments that stressors were in the periphery in his 1979 model because he at that time had had his focus on resources. This shows how Antonovsky himself did not see the model as fixed once it had been described, but opened up for further developments along with new insights. 
Fig. 4.2 Mapping sentence definition of GRRs (Antonovsky, 1979, p. 103)

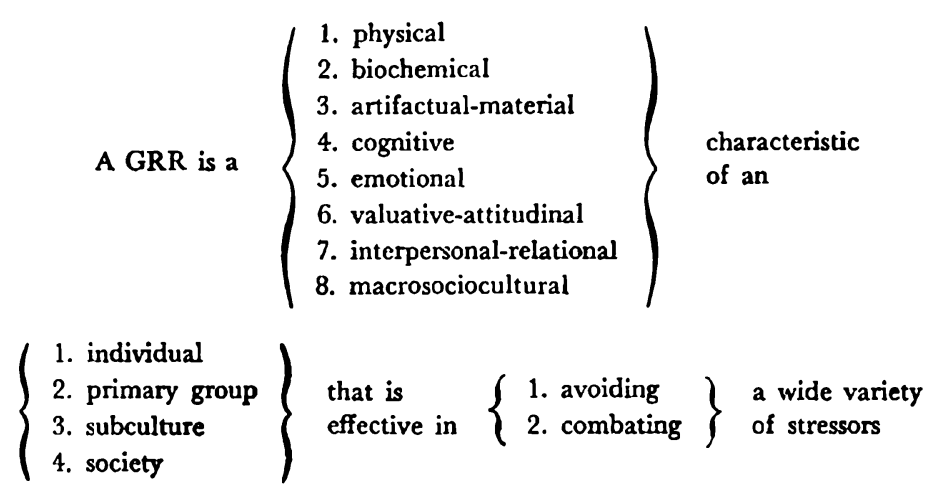

and thus preventing tension from being transformed into stress.
Antonovsky was now eager to test the new concept SOC empirically and after his return to Beersheba he developed a 29-item instrument that he felt was good. With this, he returned to Berkeley in 1983 for a second sabbatical aiming to test the questionnaire. In the meantime, he had gotten a request to write a second edition of Health, Stress and Coping, which had been well received. He proposed rather to add an epilogue chapter-which turned into a completely new book: Unravelling the mystery of health (Antonovsky, 1987). This book has a deeper treatment of the sense of coherence, and we can see the definition being expanded (Antonovsky, 1987, p. 19):

\footnotetext{
"The sense of coherence is a global orientation that expresses the extent to which one has a pervasive, enduring though dynamic feeling of confidence that (1) the stimuli deriving from one's internal and external environments in the course of living are structured, predictable, and explicable; (2) the resources are available to one to meet the demands posed by these stimuli; and (3) these demands are challenges, worthy of investment and engagement."
}

In 1990, Antonovsky still remains with this definition and comments that element (1) comprehensibility and (2) manageability were present in the 1979 definition, but that element (3) meaningfulness is new, and that this element grew steadily more important in his thinking (Antonovsky, 1990, p. 78). He also commented that the second definition therefore has less of a cognitive emphasis than the initial one. The process of operationalizing the concept to be able to test the model leads Antonovsky to become aware of its inadequacies. He narrates that he also at the time had become aware of the works of Moos (Moos, 1984, 1985), Kobasa (1979, 1982), and Victor Frankl (Frankl, 1975), which he believed, in his terms, were working on the salutogenic problem (Antonovsky, 1990). In the 1979 version of the SOC definition, he was clearly influenced by systems theory and ideas of order and disorder, and he gave much room to outlining the first component comprehensibility. A person could not deal with a stressor unless one felt one had a clear understanding of the character of the problem at hand. In delineating the second component manageability, he was inspired by the work on mastery and coping, particularly locus of control (Rotter, 1966). As he continued to deepen his understanding of coping it became, in Unraveling the mystery of health, important to him to underline that the crucial thing about manageability is the sense that adequate resources to cope with stressors are to be found either: "....in one's own hands or in the hands of legitimate others" (Antonovsky, 1990, p. 79). The third component meaningfulness is new and delineated fully in the 1987 book. It had been mentioned only briefly in 1979, and phrases such as the world makes sense was primarily used to describe a cognitive perception of order. Inspired by the work of for instance Victor Frankl, Antonovsky now understands meaningfulness in the emotional sense as a way of looking at life as worth living, providing the motivational force: "... which leads one to seek to order the world and to transform resources from potential to actuality" (Antonovsky, 1990, p. 79).

Antonovsky used the terms entropy and negative entropy (negentropy) to explore and describe the connection between chaos and order, and he argued that systems theory certainly is a valuable theoretical framework for understanding sense of coherence as an answer to the quest creating order out of chaos. Throughout Health, Stress, and Coping Antonovsky's concern was the SOC of individuals, he only loosely suggested that the concept could be employed at the social level. In Unravelling the Mystery of Health, he questioned this assumption and discussed the SOC as a group property more in depth. Rhetorically he asks (Antonovsky, 1987, p. 170): "Is it too grandiose an ambition to set as a goal moving closer to an integrated theory that proposes how any system copes with its reality?" Antonovsky discussed relevant preconditions, or dimensions for it to be meaningful to talk of a group SOC. He considered size as the most crucial parameter, and he was quite assured that SOC would be an 

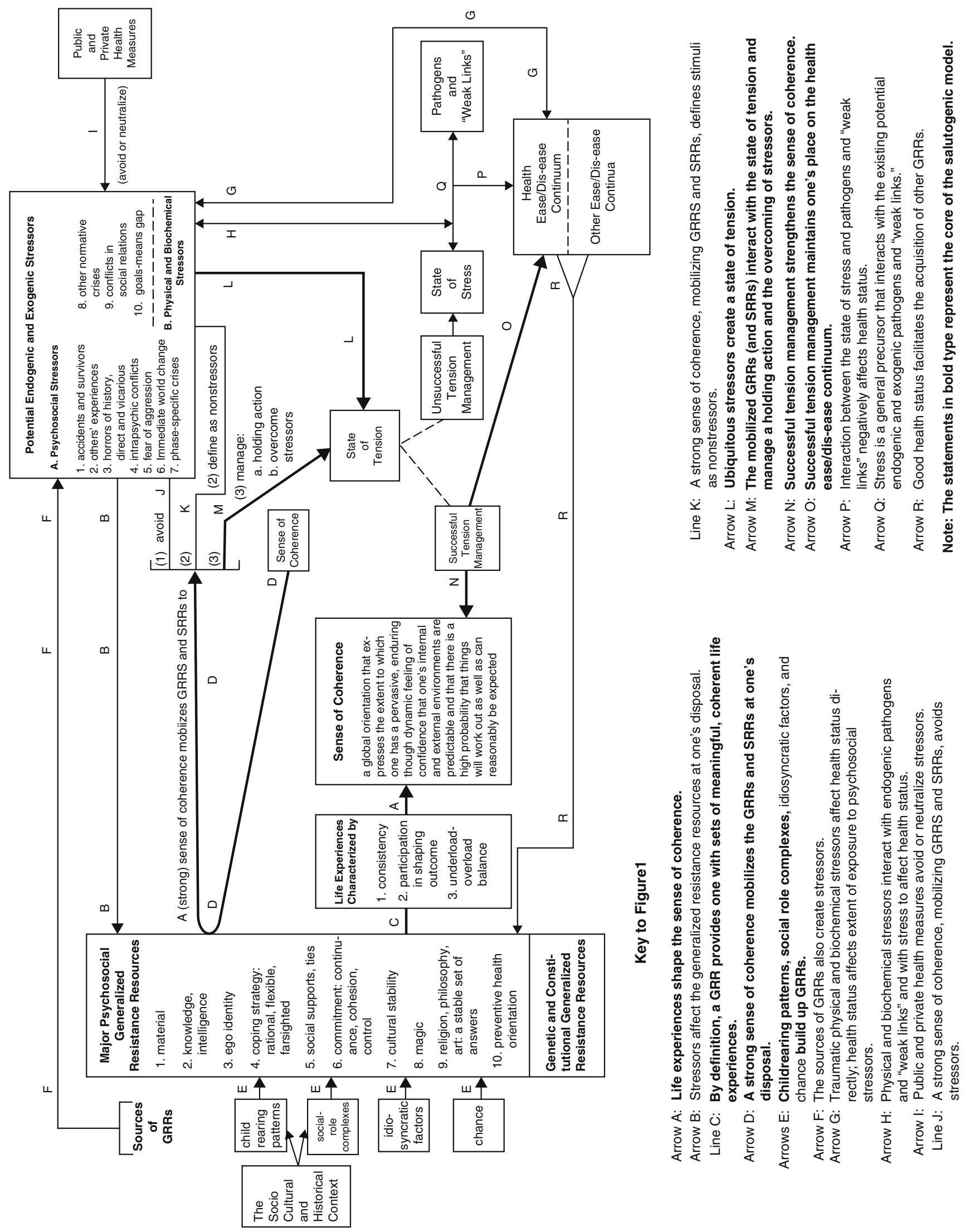

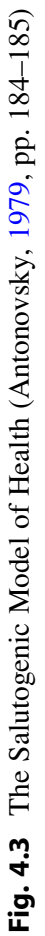


emergent group property in primary groups such as the family, a small local community, a work or a friendship group or the like. However, he felt increasingly less confident about whether SOC “... is applicable to a large-scale, complex, diversified collectivity" (1987, p. 175). He made a distinction however, between collectivities that are social categories, and collectivities that are associational in character, arguing that there must be a sense of group consciousness, a subjectively identifiable collectivity, before it makes sense, or is even possible to talk of a group SOC. Still, Antonovsky emphasized, the size of the group and a sense of group consciousness will not indicate whether the group has a weak or a strong SOC. He suggested that a group with a strong SOC would be characterized by (Antonovsky, 1987, p. 174): “A group whose individual members tend to perceive the collectivity as one that views the world as comprehensible, manageable, and meaningful, and among whom there is a high degree of consensus in these perceptions." Describing it like this, one has to move beyond the mere aggregation of data on the SOC of individuals in a group, and take into account the perceptions by individual members of the group of how the group sees the world. In addition, he claimed one also has to consider the extent of the consensus of the perceptions by looking at the variance of individual scores.

Antonovsky (1987, p. 176) brought forth yet two relevant dimensions for group SOC (1) the duration of the existence of an identifiable collectivity and (2) that membership in the collectivity is of overriding centrality in the life of each member, and to such an extent that the self and the social identity are deeply interwoven. His argument about the duration of the existence of the group is closely tied to his hypothesis that SOC is a rather stable property for an individual, and that one's location on the continuum will not change much after one has reached the age of thirty. He thus argued that it would be difficult to imagine a group SOC, strong or weak, if the social context and conditions were not relatively stable and consistent over several years. The prerequisite of a yearlong group duration implies that there most likely will be turnover among the individual members of the group. However, the turnover must not unsettle the stability and consistency of the collectivity. The subjectively identifiable group must remain (Antonovsky, 1987, p. 176). A final important possibility of the group SOC raised by Antonovsky is whether it makes a difference to an individual's health to belong to a group or groups with a weak or strong SOC. He asks (Antonovsky, 1996a, p. 17): "What is the relationship between the movement of the person toward wellbeing and the strength of his/her collective SOC?" His hypothesis is that, yes, it makes a difference in terms of health prediction, beyond merely knowing the SOC level of the person. First, because of the importance of the social environment in giving experiences that are decisive to the development of a strong or weak SOC. He emphasized that groups with a strong SOC tend to structure situations and thus provide experiences that over time will enhance the SOC of the group's individual members. Second, and even more important he believes, in order to cope with some stressors interventions are required by collectivities rather than by individuals, pointing to working life as an illustrative example (Antonovsky, 1987, p. 178). Some stressors stem from conditions deeply rooted in organizations, and/or in the structure of society and confront the entire collectivity, and therefore call for group resources to be properly dealt with. It is about the group's ability to mobilize and activate its collective resources to confront the problem and relieve tension, more than the person needing the group to confront a stressor that he/she cannot deal with alone. In such cases, the individual SOC is relevant and important in regulation of emotion. In coping with the collective stressor directly, Antonovsky claims (1987, pp. 178-179):

\footnotetext{
"... it is what the group does that matter. . Only individuals are more or less healthy, depending, among other things, on how well they manage tension, but in the face of collective stressors, the strength of the group, rather than of the individual, SOC is often decisive in tension management."
}

Through his arguing Antonovsky tried to make sense of SOC as a group property by use of quantitative measures, which of course reflects his training and the dominant way of doing science at the time. Yet, he claimed that the ontological beliefs of entropy and negentropy and the search for order out of chaos require multiple approaches across disciplines. His idea of taking into account the perceptions by individual members of the group, points in the direction of qualitative research. His suggestion to move beyond aggregated individual SOC data and to deal with the cultural production of the group as a source of data for understanding group SOC does the same. He advocated observing collective behavior such as myths, rituals, humor, language, ceremonies, and so on of the group (Antonovsky, 1987, p. 176), and by that, as we understand it, he is calling for a variety of methodological approaches. This is a call, which possibly has better circumstances to be answered in our time than in his.

\section{Tuning the Model: General Resistance Resources-General Resistance Deficits}

Another of the elements in the SMH which he did change his conceptualization of in the 1987 book was stressors. In 1979, he was quoting Lazarus and Cohen (1977, p. 109) and defined stressors as: "A stimulus which poses a demand to which one has no ready-made, immediately available and adequate response" (Antonovsky, 1979, p. 72). The strength 
of this definition, according to Antonovsky, was that one could classify stimuli without knowing the consequenceswhether tension is transformed into stress or not. However, in 1987 , he linked the definition of stressors to resources. He claimed that the absence of a GRR could become a stressor (Antonovsky, 1987, p. 28). One illustrative example here could be the absence of money (authors' comment). Such an absence of resources he called Generalized Resistance Deficit (GRD). He suggested that the total stressor-resource situation (GRR-GRD) could be captured by a continuum, with many potential subcontinua (Antonovsky 1987, p. 28):

\begin{abstract}
"I propose then, that we can speak of 'major psychosocial generalized resistance resources-resistance deficits' (GRR-RDs) as one unified concept. In each case-wealth, ego strength, cultural stability, and so on-a person has can be ranked on a continuum. The higher one is on the continuum, the more likely is it that one will have the kind of life experiences that are conducive to a strong $S O C$; the lower one is, the more likely is it that the life experiences one undergoes will be conducive to a weak SOC. A stressor, in sum, can be defined as a characteristic that introduces entropy into the system - that is, a life experience characterized by inconsistency, under-or overload, and exclusion from participation in decision-making."
\end{abstract}

Thus, any phenomenon can be characterized by the degree to which it creates these three important life experiences: consistency, load balance, and participation in decision-making. These are the life experiences conducive to SOC, and every individual can be placed on a continuum for each of these life experiences. If an experience is toward the fortunate end of these continua it indicates the existence and use of GRRs, if it is toward the unfortunate end it indicates the lack of GRRs and thus a GRD. Antonovsky was optimistic for the utility of this new reconceptualization of stressors (Antonovsky, 1987, pp. 30-31):

\footnotetext{
"Subsuming the stressors, and particularly chronic, endemic stressors, under the overarching concept of GRR-RDs provides a theoretical basis for constructing a measurement tool that links the resources and stressors-would that I could coin a single word! - through the SOC to health outcome."
}

This highlights Antonovsky's understanding of not focusing on stressors alone, not focusing on resources alone, but focusing on their combined effect to create life experiences that are characterized by consistency, load balance, and participation in decision making. Such experiences are conducive to a high SOC, and therefore move a person toward health.

The SMH demonstrates that sense of coherence and different resistance resources work together in a mutual interplay. The more resistance resources people are conscious of and are able to mobilize and make use of, the higher SOC. A higher SOC will in turn help people mobilize more of their resources, leading to better health and well-being. Thus, SOC is flexible rather than being constructed around a fixed set of dominant strategies such as the classic coping strategies (Antonovsky, 1987, 1992, 1993). Antonovsky lists a spectrum of ways in which SOC affects health (Antonovsky, 1990, p. 78):

- SOC leads one to engage in health promoting behaviour, for instance through attitudes.

- SOC influences one's process of defining a stimulus as a stressor-nonstressor. Some stimuli might rather be seen as neutral, or even salutary.

- SOC leads one to interpret a stressor as ordered.

- SOC leads one to search one's repertoire for GRRs that are appropriate for the specific situation, including the resources available through one's network, thereby giving a flexible rather than rigid pattern of response.

- SOC-induced response patterns cause the brain to send messages to activate appropriate bodily resources.

- SOC opens one up to analysis of the results of one's behaviour and makes one ready to redesign response as needed.

- SOC makes one aware of the need to cope both instrumentally as well as emotionally.

In Chap. 5 in Unraveling the mystery of health, Antonovsky writes he believes that it is in early adulthood that one's location on the SOC continuum becomes more or less fixed. He claims that SOC developed in this period of life stabilizes and remains at this level and that only rarely might experiences in life improve the level of SOC afterward (Antonovsky, 1996b, p. 175):

"I have often committed myself, orally and in writing, to the hypothesis that the strength of a person's SOC is more or less stabilized by roughly the age of 30 , that is, when one has been in the normal work and family situation of one's culture and subculture for a number of years."

His hypothesis is based on him arguing there are no major changes in the quality of the experiences that affect the SOC after the age of 30 (Antonovsky, 1987, p. 123):

\footnotetext{
"For the middle-aged adult, the new marriage, new job, new country, new social climate, or new therapist can only at best (or at worst) begin to initiate change, insofar as this stimulus provides a different long-range set of life experiences characterized by different levels of consistency, load balance, and participation in socially valued decision making."
}

However, he emphasized that his position is a hypothesis based on theoretical considerations and is not based on empirical evidence (Antonovsky, 1996b). Further, he maintained that it is important to clarify what is meant by a major strengthening of the SOC and claims that if a substantial number of people experience a given mode of therapy and improve their SOC score by five points on the average "this is not to be sneezed at" (Antonovsky, 1996b, p. 176). Moreover, he also suggests that practitioners can arrange for SOC- enhancing experiences and he writes, "this would be 
true for any therapeutic mode that facilitates a long-lasting, consistent change in real life experiences that people undergo" (Antonovsky, 1987, p. 126).

\section{Health and Well-being: In or Off Key?}

One of Antonovsky's deviations from pathogenesis was to reject the dichotomization into categories of sick or well. Through extensive use of statistics, he argued that it is very rare indeed to be completely healthy (Antonovsky, 1979). We are rather all more or less ill or well at any given point in time-located on a health ease-dis/ease continuum from maximally ill (dis/ease pole of continuum) to maximally well (ease pole of continuum). The important point is to focus on what moves an individual toward the ease pole of the continuum, regardless of where he/she was initially located. This is the process of salutogenesis (Antonovsky, 1979, preface xiv-xv):

\section{“...I am persuaded that the salutogenic orientation, that think- ing in terms of the mystery of movement toward the ease pole of the ease-dis/ease continuum, is a significant and radically dif- ferent approach to the study of health and illness than the pathogenic orientation."}

What lies at the ease pole of the continuum is a question we will return to later. However, before moving on we will linger a bit on Antonovsky's writings on illness and disease, and on whether or not it is ok to study illness within the salutogenic paradigm. While Antonovsky stated that his thinking is greatly indebted to Dubos' work on adaptive capacity and adaptive coping, he nevertheless criticized Dubos for not going explicitly beyond the concept of multiple causation of specific diseases, though Dubos claimed this to be his main agenda. Antonovsky stated however (Antonovsky, 1972, p. 538): “...his (Dubos') focus on adaptive capacity is certainly congenial to the concept of breakdown." It seems as though Antonovsky introduced the term breakdown to have a phrasing for the process of departing (Antonovsky, 1972, p. 537): "from the social norm we call health." Whether Antonovsky meant by this that breakdown will result in various kinds of diseases and thus be, in fact, nearly synonymous with disease, or that breakdown is merely a description of the subjective experience of not feeling well (being ill)—and thus a movement toward dis/ease, is unclear. In outlining the salutogenic philosophy of life Antonovsky claimed that entropy is the norm and that experiences of disease and illness are to be considered requisite to the human condition. Illness, being the subjective experience of not feeling well is thus a larger and a more holistic experience than a specific disease, is it not? Inferring, one can indeed experience dis/ease and or illness without being diagnosed with a disease. Breakdown may or may not include having a particular disease, but will it not always include experiences of dis/ease and illness?

Despite Antonovsky's intention of going beyond the dichotomy of healthy/sick in the pathogenic paradigm, it is as though he remained within the paradigm when using the terms illness and disease interchangeably. Did he mean that the movement toward the ease pole is a salutogenic movement, whereas the movement toward the dis/ease pole is a pathogenic one (Antonovsky, 1979, p. 69):

\footnotetext{
"Inevitably, both because I have been conditioned as well as everyone else by the question of pathogenesis and because the overwhelming part of the data available asks this question, I too shall slip into asking, Why are people located on-or why do they move down toward the dis/ease end of the continuum? I shall seek to avoid doing so and ask the reader to join me in this effort."
}

Alternatively, did he find it worthwhile and relevant to study movements toward the dis/ease pole of the ease-dis/ ease continuum within the salutogenic orientation (Antonovsky, 1979, p. 37): "Salutogenesis asks, what are the factors pushing this person towards this end or towards that end of the continuum." Engaging in this effort has perhaps nothing to do with pathogenesis as such. Maybe it is of import for understanding health-promoting processes. As apparent from the two quotations above Antonovsky seemed unclear and to contradict himself on this. Taking Antonovsky's own critique of Dubos into account, it is tempting to root for breakdown being the salutogenic paradigm's counterpart to disease in the pathogenic paradigm; namely the subjective experience of being ill, including periods of having diseases in a pathogenic sense. However, this remains unclear in Antonovsky's own texts, and there are examples in the literature of different interpretations of his writings on this topic.

A second deviation from the pathogenic orientation was the rejection of the medical expert as the judge of who is sick or well, through the focus on disease and diagnosis. Such an approach, Antonovsky stated $(1979$, p. 36): "blinds us to the subjective interpretation of the state of affairs of the person who is ill". In the health ease-dis/ease continuum, we find this expressed in the slash in dis/ease: dis/ease infers the subjective experience of illness, possibly including periods of being sick and diagnosed in the pathogenic sense. This is also evident from the operationalization of health that is found in Fig. 4.1, which clearly demonstrates that Antonovsky advocated for a health concept that included subjective judgment. Thus, to understand health in the salutogenic paradigm we seem to need to define illness explicitly and differently than being sick because of diagnosis. Given the focus on subjective interpretation of health and a movement in a positive direction, it could easily (and mistakenly) be assumed that Antonovsky was a proponent for the concept of positive health. Quite opposite to this, he 
stated that (1979, p. 52): "the resemblance between the focus on positive health and the problem of salutogenesis is quite superficial." He strongly opposed the WHO definition of health that states, "Health is a state of complete physical, mental and social well-being and not merely the absence of disease or infirmity" (WHO, 1948). Antonovsky gave several reasons for his opposition to this definition of health: it cannot be operationalized and therefore cannot be measured, it is too optimistic without dynamic reference to the struggles of life, and most importantly: it opens up for "medical imperialism" (Antonovsky, 1979, p. 53). This is a point Antonovsky felt strongly about (1979, pp. 53-54):

\begin{abstract}
"Whatever the powers that be do not like enters the proper sphere of medicine: political dissent, whatever the social system, has led to locking people up "for their own good"; and sex education, family planning and abortion, divorce and homosexuality, along with underachievers and overachievers, dropouts and jocks and grinds-all these and many more fall within the province of health with the blessings of WHO."
\end{abstract}

The skepticism to WHO's broad health concept that necessitates value judgment (including social and mental well-being in the wider sense) made Antonovsky advocate for a more precise definition of health. A more limited definition of health would be measurable and therefore useful in empirical research, and not less importantly limit the scope of the "proper sphere of medicine" and the possibilities of the power abuse which history warns us about. His operationalization of the health ease-dis/ease continuum (Fig. 4.1) demonstrates this wish for a rather precise definition of health, avoiding the imprecision of a positive dimension. A closer look at this figure reveals that a maximum state of health according to Antonovsky is a score of 1 on each of the components (1-1-1-1): no pain (by subjective judgment), no functional limitation (by subjective judgment), no medically defined condition (by health authority judgment), and no treatment needed (by health authority judgment). This is a negative definition of health, in that it is based on absence of certain characteristics-it is not more than "the absence of disease or infirmity."

However, still in 1979, he made one interesting comment on what can potentially be found at the maximum ease pole of the health ease-dis/ease continuum. He acknowledges that this continuum seems to formulate the most desirable health category in negative terms. And he opens for a possibility of going beyond the negative even if he does not take great interest in this himself, because "the salutogenic orientation is not concerned primarily with explaining how people reach perfect health - at best, a heuristic notion" (Antonovsky, 1979, p. 67) and continues:

\footnotetext{
"Yet it may be valuable, if we are to study really healthy people, few as they are, to have some way of identifying them beyond the 1-1-1-1 category. To this end, I would propose an additional question, to be asked after the first four questions have been
}

answered with the first alternative in each case: "You have said that your state of health is not painful and imposes no limitations. The doctor's report gives you a clean bill of health. But these are negative things. Would you say that your state of health goes beyond this, that you feel an abundance of energy, that you are what people call a picture of perfect health?"

Did Antonovsky stick to this understanding of health throughout his authorship, or did his view develop after these early statements in 1979? As late as in 1995 (in a paper published a few months after his death), he repeated the arguments from 1979, warning against a value-based definition of health. In this paper, he used Nazi doctors as an example of how alleged deviants were tortured not only for the sake of other peoples' health, but sometimes even for their own good. He wrote about his wish for research that would define health relatively narrowly and "far from coextensively with all of well-being or happiness" (Antonovsky, 1995, p. 10). He believed this was vital to avoid blurring the line between SOC and health, to distinguish health from other aspects of well-being, and to protect against using salutogenesis to pressure people to live moral lives. He warned against the danger of assuming that "the morally good is salutary" (ibid, p. 11). The morally good might be quite the opposite of salutary, as in the sacrifice of one's own health for the good of others. Moreover, the salutary might be morally repugnant, as in the case of persons who harm others, with the help of their strong SOC. He pointed out, however, that he often found himself in a bind as a teacher of medical students. In spite of his above-mentioned arguments, he thought (Antonovsky, 1979, p. 67): "it is crucial that they learn to see health in a broad context going far beyond the physiological level." He emphasized that seeing health in a broad context entailed moving beyond a post Cartesian dualism and taking into account fantasy, love, playing, meaning, will and the social structures that promotes these (Antonovsky, 1987).

Antonovsky did write about well-being. However, he warned about confusing well-being with the definition of health (Antonovsky, 1979, p. 197):

\footnotetext{
"I have insisted that the health ease-dis/ease continuum is not to be regarded as coextensive with the entire realm of well-being. Other ease-dis/ease continua exist (...) a nod has (then) been made in their direction; they are highly relevant to and intertwined with health, but they are distinct (...) If our interest are in understanding health, then location on the familyrelations or social-relations or material-resources ease-dis/ ease continua can usefully be viewed as a GRR."
}

One possible interpretation of this is that Antonovsky was of the opinion that only physiological health was captured under the health ease-dis/ease continuum and part of his operationalization thereof. He warned against dangers related to classifying mental and social well-being as elements of health, as that would open up for medical imperialism. However, he was positive to the concept of well- 
being as something wider ("the entire realm of well-being"), of which health as he defined it was only one dimension. That could be why he so often specified it as the health easedis/ease continuum - other continua exist. Regarding social well-being, Antonovsky seems quite willing to classify a variety of social ease-dis/ease continua as GRRs, for instance for family relations and social relations (see quotation above, 1979, p. 197).

When it came to mental health, however, Antonovsky contradicted himself, and admitted to it. He wrote (Antonovsky 1985, p. 274):

\begin{abstract}
"Mental health, as I conceive it, refers to the location, at any point in the life cycle, of a person on a continuum which ranges from excruciating emotional pain and total psychological malfunctioning at one extreme to a full, vibrant sense of psychological wellbeing at the other."
\end{abstract}

Antonovsky describes the movement on the continuum toward better mental health as shifting, and continues:

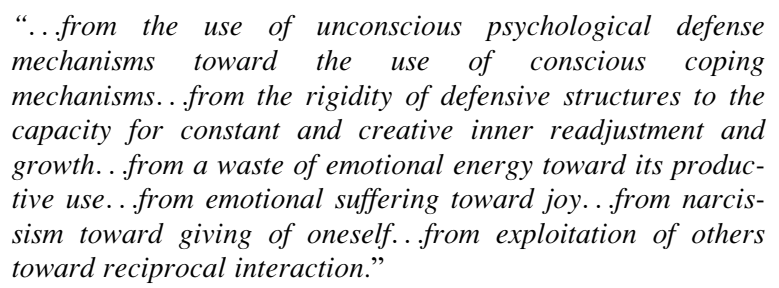

Later he commented on himself that this was a valuebased definition (Antonovsky, 1995, p. 9):

"I have made an attempt in print to formally define mental health (...). Was I not, by definition, requiring that to be mentally healthy, a person be someone whom I (or even most others) liked, respected, admired?"

While Antonovsky's treatment of the concept of health is extensive and at times bewildering, it seems safe to conclude that his main messages remained the same throughout his authorship. Health is part of a larger realm of well-being. Health is best understood as a continuum, not as a dichotomy. Health must be narrowly defined to facilitate for empirical research and to avoid value-based definitions that might open up for the abuse of power. Further, although unclear, he seemed to believe that salutogenesis is about focusing on the movement toward the ease pole of the health ease-dis/ease continuum-regardless of how far into the positive that continuum might stretch. While advocating a narrow physiological definition of health when debating health and moral, in other texts he broadens the scope and writes (Antonovsky, 1996a, p. 13): "It (the SMH) is, however, not a theory which focuses on "keeping people "well". Rather, (...) it is a theory of the health of that complex system, the human being", indicating an ecological understanding of health. This understanding is apparent also in citations as the following (Antonovsky 1994, p. 10):

\begin{abstract}
"The study of the macrosocial is essential to understanding movement toward health ... (but) a sensitivity to the macrosocial is only a point of departure. What is required is a systematic framework within which structural sources of health can be understood."
\end{abstract}

These quotations make us leave the presentation of health and well-being on a somewhat uncertain and off-key note. Nevertheless, the very same statements demonstrate that the $\mathrm{SMH}$ and Antonovsky were in tune with the core values of health promotion.

\section{Harmonizing: SMH's Relevance for Health Promotion}

In Unraveling the mystery of health, Antonovsky starts with a detailed and explicit explanation of why he is persuaded that the salutogenic orientation is a radically different approach than the pathogenic orientation. Through six different aspects, he illustrates the distinction between salutogenesis and pathogenesis as he sees it (Fig. 4.4). He claims these aspects have implications for research, for understanding health and illness, and for clinical practice. Antonovsky's fundamental philosophical assumption is that all human beings are in the river of life. Nobody stays on the shore. Much of the river is polluted, literally and figuratively. There are forks in the river that leads to gentle streams or to dangerous rapids and whirlpools and the
Fig. 4.4 A summary of six main aspects of the salutogenic and the pathogenic orientation as presented by Antonovsky in Unravelling the Mystery of Health (Antonovsky, 1987). The authors' illustration

\begin{tabular}{|l|l|}
\hline SALUTOGENIC ORIENTATION & PATHOGENIC ORIENTATION \\
\hline Heterostasis & Homeostasis \\
\hline $\begin{array}{l}\text { 1. Health ease - dis/ease continuum } \\
\text { 2. The history of the person }\end{array}$ & $\begin{array}{l}\text { 1. Healthy/sick dicotomy } \\
\text { 2. The person's disease/diagnosis }\end{array}$ \\
$\begin{array}{ll}\text { 3. Salutary factors } & \text { 3. Risk factors } \\
\text { 4. Stressors and tension might be } & \text { 4. Stress is pathogenic }\end{array}$ \\
$\begin{array}{l}\text { 5. Active adaptation } \\
\text { 6. The "deviant" case }\end{array}$ & $\begin{array}{l}\text { 5. The magic bullet } \\
\text { 6. Hypothesis confirmation }\end{array}$ \\
\hline
\end{tabular}


crucial questions is "What shapes one's ability to swim well?" (Antonovsky, 1987, p. 90). This metaphor illustrates that heterostasis and not homeostasis is the prototypical characteristic of the living organism. The daily structures in which we are all embedded are unavoidably and unendingly stressful.

The first aspect Antonovsky asserts as important to health promotion is understanding health as a continuum, and not as a dichotomy between sick and healthy people. He emphasises that in order to explain health one will have to study the movement toward the ease pole of the health ease/ dis-ease continuum. His focus is on the dynamic interaction between health-promoting factors and stressors in human life, and on how people may move to the healthy end of the health ease - dis/ease continuum. A sense of coherence is proposed to be the significant variable in effecting this movement (Antonovsky 1985).

The second aspect is to focus on people's own story and not only the diagnosis. He emphasises that to listen to a person's own story (Antonovsky, 1987, p. 5):

\section{“...it does not guarantee problem solution of the complex circularities of people's lives, but at the very least it leads to a more profound understanding and knowledge, a prerequisite for moving toward the healthy end of the continuum."}

Further in the third aspect he underscores the importance of salutary factors when focusing on promoting movement toward better health, his claim being that salutary factors contribute directly to health (Antonovsky, 1996a, p. 14):.

\begin{abstract}
"Posing the salutogenic question, namely, 'how can we understand movement of people in the direction of the health end of the continuum?'-note all people, wherever they are at any given time, from the terminal patient to the vigorous adolescent-we cannot be content with answer limited to 'by being low on risk factors'... To answer the question requires another neologism: salutary factors. I will not quarrel with 'healthpromoting' factors or any other term, as long as the concept is clear: factors which are negentropic, actively promote health, rather than just being low on risk factors."
\end{abstract}

Health is thus, according to Antonovsky, much more than being low on risk factors. In the fourth aspect, he explains the view on stress and claims that stress might be pathogenic, neutral, or salutogenic. Because stress is ubiquitous, salutogenesis opens up for the rehabilitation of stressors in human life. The fifth aspect is related to the view on therapy. In salutogenesis, the ideal in therapy is the person's (he does not use the word patient) ability to actively adapt and not the magic bullet meaning that based on the right diagnosis you search to find the right cure as in medication or surgery. To underline the significance of active adaptation as ideal in therapy he writes (Antonovsky, 1987, p. 9):

\footnotetext{
"When one searches for effective adaptation of the organism, one can move beyond post-Cartesian dualism and look to imagination, love, play, meaning, will, and the social structures that foster them."
}

The last and sixth aspect is about the focus in research and Antonovsky asks whether we are looking for the deviant case or hypothesis confirmation. He uses an example to illustrate his point: a confirmed hypothesis is that depression is predictive of cancer mortality. However, the difference between the depressed and nondepressed that died of cancer is respectively $7.1 \%$ and $3.4 \%$, inferring that the great majority did not die of cancer and this is the deviant case. Consequently, he claims, it is possible to generate hypotheses to explain salutogenesis (Antonovsky, 1987).

In a paper from 1996, he argued that the salutogenic orientation can be a basis for health promotion, and in being so, it (Antonovsky, 1996a, p. 14): "directs both research and action efforts to encompass all persons, wherever they are on the continuum, and to focus on salutary factors." A third weighty inference of embracing a salutogenic orientation in health promotion, he continued, is the orientations' focus on the history of the person and not on the persons' diagnosis and disease. He claims this to be a moral stance, and it to be (ibid.): "impermissible to identify a rich, complex human being with a particular pathology, disability or characteristic." Whereas those working within the pathogenic orientation are pressured to forget the complexity of the human being, the health promoter is, and should be, pressured to relate to all aspects of the person (or collective) to help him/her move toward the ease end of the continuum. Consequently this issue is not only moral it is also scientific (Antonovsky, 1996a). Antonovsky firmly asserted that a salutogenic orientation offers direction and focus for health promotion, and he stated that the salutogenic model could be a foundation for the development of a theory that will be productive in this specific field (Antonovsky, 1996a, p. 18): "The salutogenic model, I believe, is useful for all fields of health care. In its very spirit, however, it is particularly appropriate to health promotion."

\section{Conclusions}

Diving into Antonovsky's writings, trying to provide an overview of his salutogenic model of health has been not only challenging, but also utterly worthwhile. Overall, it has been an interesting, and for most parts, salutary learning process. We feel safe and supported by Antonovsky when we urge you all to keep reflecting, researching, and further developing the SMH. Antonovsky claims that one of the advantages of the model is just that, that it allows us, indeed even stimulates us, to ask questions, whatever the answers turn out to be.

We want to wrap this chapter up the way we started, with Antonovsky's own words (1987, preface xvii):

\footnotetext{
"If I have been motivated by one purpose to write this volume, it is to reinforce those who are already at work - to spark ideas in the minds of those colleagues who share with me the enchantment with the mystery of health."
} 
Open Access This chapter is distributed under the terms of the Creative Commons Attribution-Noncommercial 2.5 License (http:// creativecommons.org/licenses/by-nc/2.5/) which permits any noncommercial use, distribution, and reproduction in any medium, provided the original author(s) and source are credited.

The images or other third party material in this chapter are included in the work's Creative Commons license, unless indicated otherwise in the credit line; if such material is not included in the work's Creative Commons license and the respective action is not permitted by statutory regulation, users will need to obtain permission from the license holder to duplicate, adapt or reproduce the material.

\section{References}

Antonovsky, A. (1961). The early Jewish labor movement in the United States. New York: YIVO Institute for Jewish Research.

Antonovsky, A. (1967a). Social class and illness: A reconsideration. Sociological Inquiry, 37, 311-322.

Antonovsky, A. (1967b). Social class, life expectancy and overall mortality. Milbank Memorial Fund Quarterly, 45, 31-73.

Antonovsky, A. (1968). Social class and the major cardiovascular diseases. Journal of Chronic Diseases, 21, 65-106.

Antonovsky, A. (1971). Social and cultural factors in coronary heart disease. An Israel-North American sibling study. Israel Journal of Medical Sciences, 7(12), 1578-1583.

Antonovsky, A. (1972). Breakdown: A needed fourth step in the conceptual armamentarium of modern medicine. Social Science \& Medicine, 6(5), 537-544. doi:10.1016/0037-7856(72)90070-4.

Antonovsky, A. (1974). Conceptual and methodological problems in the study of resistance resources and stressful life events. In B. Dohrenwend \& B. Dohrenwend (Eds.), Stressful life events: Their nature and effects. New York: Wiley.

Antonovsky, A. (1979). Health, stress, and coping. San Francisco: Jossey-Bass.

Antonovsky, A. (1985). The life cycle, mental health and the sense of coherence. Isreal Journal of psychiatry and related sciences, 22(4), 273-280.

Antonovsky, A. (1987). Unraveling the mystery of health: How people manage stress and stay well. San Francisco: Jossey-Bass.

Antonovsky, A. (1990). A somewhat personal odyssey in studying the stress process. Stress Medicine, 6(2), 71-80.

Antonovsky, A. (1992). Can attitudes contribute to health? Advances, 8 (4), 33-49.

Antonovsky, A. (1993). The implications of salutogenesis: An outsider's view. In A. P. Thurnbull, J. M. Patterson, S. K. Behr, D. L. Murphy, J. G. Marquis, \& M. J. Blue-Banning (Eds.), Cognitive coping, families and disability (pp. 111-122). Baltimore: Brooks.

Antonovsky, A. (1994). A sociological critique of the "well-being" movement. Advances, 10(3), 6-12.

Antonovsky, A. (1995). The moral and the healthy: Identical, overlapping or orthogonal? The Israel Journal of Psychiatry and Related Sciences, 32(1), 5-13.

Antonovsky, A. (1996a). The salutogenic model as a theory to guide health promotion. Health Promotion International, 11(1), 11-18.
Antonovsky, A. (1996b). The sense of coherence-An historical and future perspective. Journal of Medical Sciences, 32(3-4), 170-178.

Antonovsky, A., \& Kats, R. (1967). The life crisis history of a tool in epidemiological research. Journal of Health and Social Behavior, 8 (1), 15-21. doi:10.2307/2948487.

Antonovsky, A., Leibowitz, U., Smith, H. A., Medalie, J. M., Balogh, M., Kats, R., et al. (1965). Epidemiologic study of multiple sclerosis in Israel. An overall review of methods and findings. Archives of Neurology, 13, 183-193.

Antonovsky, A., \& Lorwin, L. (1959). Discrimination and low incomes. New York: New York State Commission Against Discrimination.

Antonovsky, A., Maoz, B., Dowty, N., \& Wijsenbeek, H. (1971). Twenty-five years later: A limited study of the concentration camp experience. Social Psychiatry, 6(4), 186-193.

Cassel, J. (1976). The contribution of the social environment to host resistance. American Journal of Epidemiology, 104(2), 107-123.

Dubos, R. J. (1960). The mirage of health. London: Allen \& Unwin.

Frankl, V. (1975). The unconscious god. New York: Simon \& Schuster.

Hollingshead, A. B., \& Redlich, F. C. (1958). Social class and mental illness: A community study. New York: Wiley.

Kardiner, A., \& Ovesey, L. (1951). A psychosocial study of the American Negro. New York: Norton.

Kobasa, S. C. (1979). Stressful life events, personality, and health. Journal of Personality and Social Psychology, 37(1), 1-11.

Kobasa, S. C. (1982). The hardy personality: Toward a social psychology of stress and health. In G. S. Sanders \& J. Suls (Eds.), Social psychology of health and illness. Hillsdale: Erlbaum.

Kosa, J., Antonovsky, A., \& Zola, I. K. (1969). Poverty and health: A sociological analysis. Cambridge, MA: Harvard University Press.

Lazarus, R. S., \& Cohen, J. B. (1977). Environmental stress. In I. Altman \& J. F. Wohlwill (Eds.), Human behavior and environment. New York: Plenum.

Moos, R. H. (1984). Context and coping: Toward a unifying conceptual framework. American Journal of Community Psychology, 12(1), $5-25$.

Moos, R. H. (1985). Creating healthy human contexts: Environmental and individual strategies. In J. C. Rosen \& L. J. Solomon (Eds.), Prevention in health psychology. Hanover: University Press of New England.

Parsons, T. (1951). The social system. New York: Free Press.

Rotter, J. B. (1966). Generalized expectancies for internal versus external control of reinforcement. Psychological Monograph: General and Applied, 80(1), 1-28.

Schuval, J. T., Antonovsky, A., \& Davies, A. M. (1970). Social functions of medical practice: Doctor-Patient relationships in Israel. San Francisco: Jossey-Bass.

Selye, H. (1956). The stress of life. New York: McGraw-Hill.

Selye, H. (1975). Confusion and controversy in the stress field. Journal of Human Stress, 1(2), 37-44.

WHO. (1948). WHO definition of health: Preamble to the constitution of the World Health Organization as adopted by the International Health Conference, New York, 19-22 June 1946; signed on 22 July 1946 by the representatives of 61 States (official records of the World Health Organization, no. 2, p. 100) and entered into force on 7 April 1948. Retrieved March 19, 2014, from http://www.who.int. 